\title{
Inverse Relationship Between Physical Activity, Adiposity and Arterial Stiffness in Healthy Middle-aged Subjects
}

\author{
Oscar Mac Ananey \\ Technological University Dublin, oscar.macananey@tudublin.ie \\ B Mc Loughlin \\ Tallaght Hospital \\ A Leonard \\ Tallaght Hospital
}

See next page for additional authors

Follow this and additional works at: https://arrow.tudublin.ie/scschbioart

Part of the Circulatory and Respiratory Physiology Commons, and the Medical Physiology Commons

\section{Recommended Citation}

Mac Ananey, O. et al. Inverse Relationship Between Physical Activity, Adiposity and Arterial Stiffness in Healthy Middle-aged Subjects. Journal of Physical Activity \& HealthMarch 2015. doi:10.1123/

jpah.2014-0395

This Article is brought to you for free and open access by the School of Biological Sciences at ARROW@TU Dublin. It has been accepted for inclusion in Articles by an authorized administrator of ARROW@TU Dublin. For more information, please contact arrow.admin@tudublin.ie, aisling.coyne@tudublin.ie,gerard.connolly@tudublin.ie.

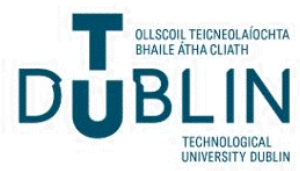


Authors

Oscar Mac Ananey, B Mc Loughlin, A Leonard, L Maher, P Gaffney, G Boran, and V Maher 


\begin{tabular}{l} 
JOURNAL of \\
Physical Activity \\
\& Health \\
\hline
\end{tabular}

\section{Inverse relationship between physical activity, adiposity and arterial stiffness in healthy middle-aged subjects}

\begin{tabular}{|r|l|}
\hline Journal: & Journal of Physical Activity \& Health \\
\hline Manuscript ID: & JPAH.2014-0395.R1 \\
\hline Manuscript Type: & Article \\
\hline Keywords: & obesity, accelerometry, cardiovascular health \\
\hline \multicolumn{2}{|l}{} \\
\hline
\end{tabular}

SCHOLARONE ${ }^{\text {M }}$

Manuscripts 
2 3

4

5

6

7

8

9

10

11

12

13

14

15

16

17

18

19

20

21

22

23

24

25

26

27

28

29

30

31

32

33

34

35

36

37

38

39

40

41

42

43

44

45

46

47

48

49

50

51

52

53

54

55

56

57

58

59

60

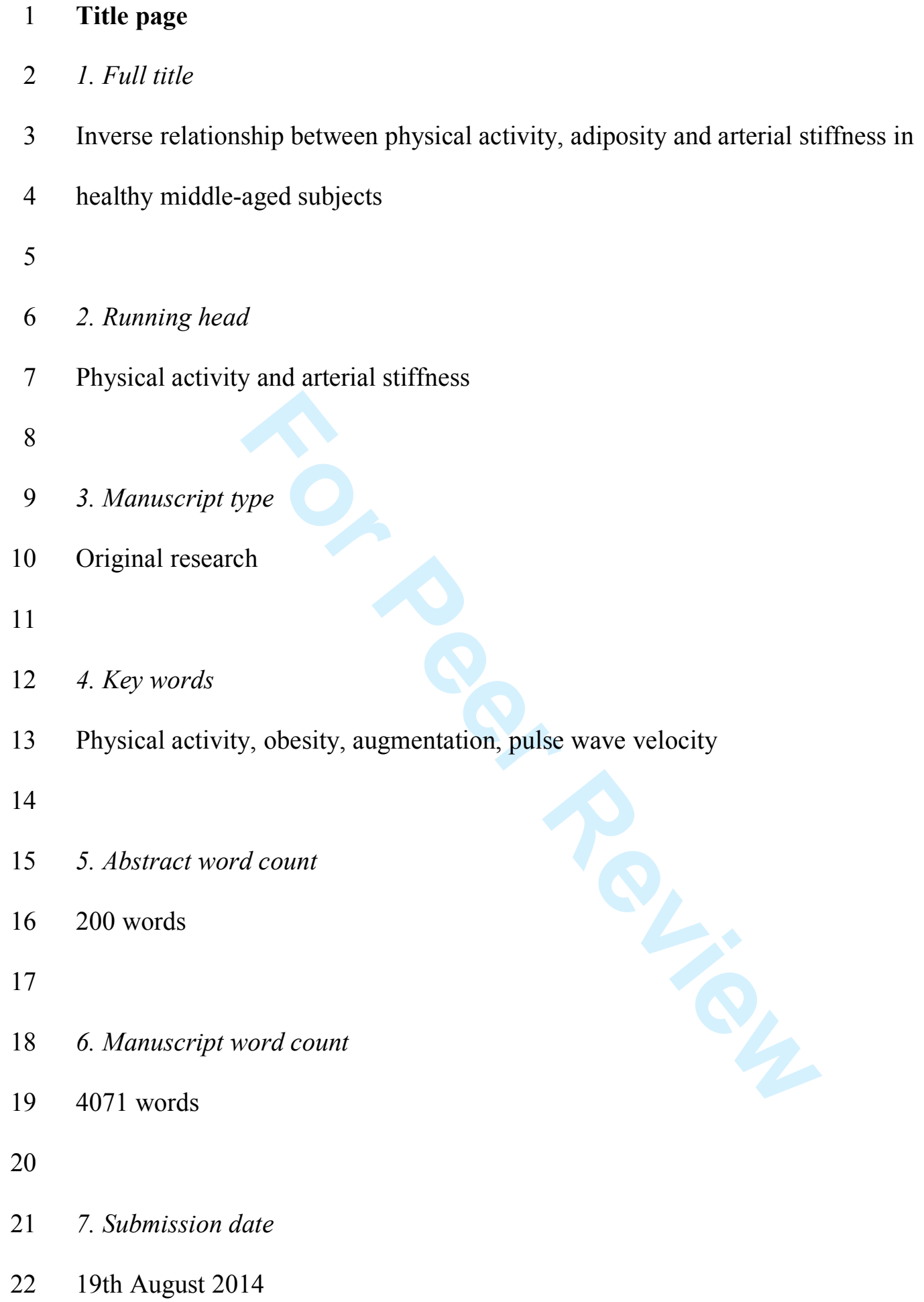


Physical activity and arterial stiffness

\section{Abstract}

24

25

26

27

28

29

30

31

32

33

34

Background: Several obesity related factors are reported to exacerbate premature arterial stiffening, including inactivity and metabolic disarray. The aim of the present study was to investigate the relationship between physical activity, arterial stiffness and adiposity using objective methods. To further explore the role of adiposity in this complex process, obesity associated anthropometric and humoral biomarkers were measured.

Methods: Seventy-nine healthy, lifelong non-smoking, subjects were recruited. Habitual physical activity was measured using accelerometry. Arterial stiffness (augmentation index; AIx \& pulse wave velocity; PWV), was measured using tonometry. Body composition was estimated using bioimpedence. Adipose associated biomarkers, leptin and adiponectin, were also measured.

Results: Sedentary time was significantly associated with AIx $(\mathrm{r}=0.38, P<0.001)$, PWV (r=0.33, $P<0.01)$, body fat composition $(\mathrm{r}=0.40, P<0.001)$ and age $(\mathrm{r}=0.30$, $P<0.01)$. Moderate + vigorous activity was inversely correlated with AIx $(\mathrm{r}=-0.28$, $P<0.05)$ body fat composition $(\mathrm{r}=-0.30, P<0.01)$, postprandial insulin $(\mathrm{r}=-0.35$, $P<0.01)$ and leptin/adiponectin ratio $(\mathrm{r}=-0.28, P<0.05)$. Moderate + Vigorous activity, body fat composition and post prandial insulin remained independent predictors of AIx but not PWV.

Conclusion: The more time healthy individuals spend being sedentary, the greater their body fat and arterial stiffness. Conversely higher activity levels are associated with reduced body fat and less arterial stiffness. 
Physical activity and arterial stiffness

49 Arterial stiffening is an independent predictor of cardiovascular risk and target organ damage such as left ventricular hypertrophy, myocardial infarction, renal failure,

51 retinopathy and vascular dementia. ${ }^{1}$ Several factors, such as smoking, metabolic 52 disease, adiposity and physical inactivity, are reported to accelerate vascular 53 stiffening. ${ }^{2,3,4,5,6,7}$ Many of these factors are inter-related with inactivity predisposing 54 to adiposity, low-grade inflammation, metabolic disarray and arterial damage. . $^{3,7,8,9,10}$ 55 In contrast, when subjects spend more time being vigorously active during 56 adolescence they have less arterial stiffness in adulthood and the observed benefits are 57 related to changes in blood pressure, body composition, cardiorespiratory fitness and 58 their metabolic profile. ${ }^{6}$ Consequently activity levels are considered of key 59 importance in maintaining metabolic and arterial health.

60 However, many studies examining the impact of physical activity on arterial stiffness 61 have used subjective questionnaires to quantify activity patterns with few studies 62 adopting more objective methods such as accelerometry. ${ }^{2,3,5,6,10,11,12}$ In addition many 63 of these studies have focused on subjects in different age/gender groups and in 64 patients with established metabolic risk factors. ${ }^{10,11,13}$

65 Therefore, the aim of the present experiment was to simultaneously evaluate the 66 association between activity levels and arterial wall changes in clinically healthy, 67 middle-aged subjects, using objective methods. In order to further explore the 68 complex relationship between physical activity, arterial wall properties and obesity, 69 we investigated if the interrelationship of activity levels and arterial changes were 70 correlated with adiposity associated anthropometric, metabolic, hormonal and 71 inflammatory markers. 
Physical activity and arterial stiffness

\section{Methods}

74 Seventy-nine (51 male \& 28 female) subjects were recruited from the general 75 population via poster advertisements in the local community within a $5 \mathrm{~km}$ radius of 76 the hospital where all the study protocols were performed. The study was approved by 77 Trinity College Dublin Ethics Committee. Written informed consent was obtained 78 from all subjects prior to testing protocols. Subjects were included if they were 79 lifelong never-smokers, free from cardiovascular disease, normotensive $(<140 / 90$ $80 \mathrm{mmHg}$ ), had normal lipid profile (LDLc $<4.0 \mathrm{mmol} . \mathrm{L}^{-1}$ ), normal oral glucose 81 tolerance test responses (fasting \& post prandial glucose $<7 \&<11 \mathrm{mmol} . \mathrm{L}^{-1}$ ) and 82 moderate alcohol intake (male $<21$ units per week; female $<14$ units per week). 83 Subjects were excluded if they were receiving treatment for or had a history of 84 hypertension, hyperlipidaemia, diabetes or were taking any medications that affected 85 haemodynamic and/or metabolic responses.

86 Following a 12-hour overnight fast, enrolled subjects attended the Cardiovascular 87 Research Unit at Tallaght hospital. Various anthropometrical measurements were 88 recorded, including height (Seca 202, SECA, UK), weight (Avery E101, Avery, UK) 89 and waist circumference (Creative Health Products, USA). Body fat composition was 90 estimated using whole-body bioimpedance (TBF 410 GS, Tanita, UK).

92 Subjects completed a 2-hour oral glucose tolerance test (OGTT). Blood glucose and 93 insulin values were measured from venous blood samples before and after a $75 \mathrm{~g}$ oral 94 glucose challenge. Homeostasis model assessment (HOMA), a measure of glycaemic 95 homeostasis, was calculated from fasting glucose and fasting insulin values (fasting 96 glucose $\times$ fasting insulin / 22.1). In addition, for each subject, glycosylated 97 haemoglobin $\left(\mathrm{HbA}_{1 \mathrm{c}}\right)$, full fasting lipid profile and the adipose associated blood 
98 markers, adiponectin and leptin were measured. Nonspecific markers of systemic

99 inflammation such as white cell count (WCC) and high sensitivity c-reactive protein

100 (hsCRP) were also measured to determine the potential impact of adipose associated

101 inflammation.

102

103

Pulse wave analysis

104 The aortic augmentation index (AIx), a measure of wave reflection and surrogate

105 marker of arterial stiffness, was calculated from pressure waveform measurements

106 recorded from the radial artery using a previously validated method (Sphygmacor,

107 AtCor Medical, Australia). ${ }^{4,14}$ Central aortic systolic and diastolic blood pressure was

108 calculated from the radial artery waveform using a previously validated transfer

109 function (Sphygmacor, AtCor Medical, Australia). ${ }^{14}$ The sphygmacor software

110 automatically generates an "operator index" as an indication of quality control. The

111 operator index is based on the pulse wave height/shape variation over ten successive

112 cardiac cycles. In the present experiment, the mean of three values with an operator

113 index $\geq 90 \%$ were used.

115 Pulse wave velocity

116 Pulse wave velocity, a direct measure of carotid-femoral arterial stiffness, was

117 calculated from simultaneous recordings of the carotid and femoral pressure

118 waveform using a previously validated semi-automated method (Vicorder, Skidmore

119 Medical, U.K.). ${ }^{15}$ Briefly, two pressure sensitive transducer cuffs were fixed to the

120 subject's neck and leg, recording the time delay $\left(\mathrm{Td} ; \mathrm{ms}^{-1}\right)$ between the carotid and

121 femoral pulse waveforms using the foot-to-foot method. ${ }^{15}$ The distance between the 
Physical activity and arterial stiffness

122 two sites was measured using a tape-measure (Dist; m). PWV was calculated by the

123 “in-built" software (Td/Dist; $\left.\mathrm{m} . \mathrm{s}^{-1}\right) .{ }^{14}$

124

125 Physical activity

126 A triaxial accelerometer (RT3, Stayhealthy, USA) was used to record routine daily

127 physical patterns. The accelerometer records activity counts as mean acceleration

$128\left(\mathrm{~m} \cdot \mathrm{s}^{-2}\right)$ in the vertical $(x)$, anteroposterior $(y)$ and mediolateral $(z)$ planes. The activity

129 counts are then summarized as vector magnitude $\left(\mathrm{VM}=\left[x^{2}+y^{2}+z^{2}\right]^{0.5}\right) .{ }^{16}$ Physical

130 activity data was recorded at 1 min intervals over seven consecutive days. A day was

131 defined as the period where $70 \%$ of the subjects had recorded accelerometer data and

$13280 \%$ of that period constituted a minimal day for inclusion in the data analysis. ${ }^{17}$ Data

133 from five consecutive days, including one weekend day (Tuesday-Saturday or

134 Sunday-Thursday), were used to calculate the absolute and relative time spent being

135 sedentary and participating in light, moderate and vigorous activity. ${ }^{18,19}$

136

137 Statistics

138 Pearson's Univariate correlation and Spearman's Univariate correlation was used to

139 examine the relationship between parametric and non-parametric data. Stepwise

140 multiple regression was used to assess the relative contribution of chosen variables

141 and arterial stiffness. An unpaired student's t-test was used to detect differences

142 between groups for normally distributed data and Wilcoxan's test for non-normally

143 distributed data. Data are presented as mean \pm SD unless otherwise stated. (JMP

144 Version 4.0, SAS Institute Inc, NC, USA).

145

146 Results

Human Kinetics, 1607 N Market St, Champaign, IL 61825 
147 The physical, metabolic, haemodynamic characteristics and gender comparisons are

148 outlined in Table 1. Similar to Irish general population averages, 53\% of the group

149 had normal BMI, 38\% were overweight and the remaining $9 \%$ were obese. ${ }^{20}$ In

150 addition, $48 \%$ of the group had a waist/height ratio $>0.5$ and had high body fat

151 composition with respect to their age and gender. Gender comparisons revealed that

152 Augmentation index was markedly higher in females compared to males, yet no

153 differences in PWV, central BP or brachial BP were observed.

154

155 All subjects had normal lipid profile, normal glycaemic profile and normal OGTT 156 responses. All subjects had normal 24-hour ambulatory blood pressure responses (Sys $157<135 / \mathrm{Dia}<85 \mathrm{mmHg}$ ) and normal arterial stiffness with respect to age and gender. ${ }^{21,22}$ 158 The non-specific markers of systemic inflammation, hsCRP and WCC, were also 159 within normal ranges.

160

161 Age was strongly correlated with both AIx $(\mathrm{r}=0.52 ; P<0.0001)$ and PWV $(\mathrm{r}=0.49$; $162 P<0.0001)$. In addition, body fat composition was strongly correlated with AIx $163(\mathrm{r}=0.55 ; P<0.0001)$ and 24 -hour ambulatory diastolic blood pressure was associated 164 with $\mathrm{PWV}(\mathrm{r}=0.25 ; P<0.05)$.

165

166 Mean daily wearing (on) duration of the accelerometer was $701 \pm 91$ min and mean 167 daily "non-wearing" (off) duration was $728 \pm 90 \mathrm{~min}$ (Figure 1a). Absolute and relative 168 time spent within activity thresholds can be seen in Figure 1b. Subjects spent $240 \pm 63$ $169 \min (16.71 \pm 4.44 \%)$ being sedentary and $448 \pm 90 \min (31.06 \pm 6.21 \%), 13 \pm 14 \min$ $170 \quad(1.45 \pm 2.23 \%) \& 4 \pm 8 \min (0.19 \pm 0.35 \%)$ participating in Light, Moderate \& Vigorous 171 activities. 
Physical activity and arterial stiffness

173 The results of the univariate correlation between the relative time spent in the four

174 activity zones (Sed, Light, Mod \& Vig) and physical measures of obesity, arterial

175 stiffness, blood pressure, metabolic and adipose related humoral markers can be seen

176 in Table 2. Time spent being sedentary was significantly associated with age, body fat

177 composition, AIx and PWV. There was a significant inverse correlation between time-

178 spent being moderately active and body fat composition and fasting insulin.

179 Subjects spent little time participating in moderate activity and 28 subjects did not

180 spend any time participating in vigorous activity. In an attempt to overcome this

181 limitation, moderate and vigorous activity time was amalgamated (Mod+Vig) in a

182 univariate analysis. Mod+Vig activity was inversely correlated with body fat

183 composition $(\mathrm{r}=-0.30, \quad P<0.01)$, postprandial insulin $\quad(\mathrm{r}=-0.35, \quad P<0.01)$,

184 leptin/adiponectin ratio $(\mathrm{r}=-0.28, P<0.05)$ and $\mathrm{AIx}(\mathrm{r}=-0.28, P<0.05)$.

185 In order to identify the relative contribution of associated variables on arterial

186 stiffness, age, gender, body fat composition, heart rate, mean arterial pressure and

187 physical activity were included in two separate stepwise regression models to predict

188 AIx and PWV. Age, gender, body fat composition and heart rate remained significant

$189(P<0.05)$ correlates of AIx for all activity zones. The combined Mod+Vig activity, but

190 not individual Sed, Light, Mod and Vig activity zones, also remained as an

191 independent predictor of AIx $(P<0.05)$. However, age remained the only significant

$192 \quad(P<0.0001)$ predictor of PWV.

193 To further identify the metabolic/hormonal consequences of physical inactivity and

194 premature arterial stiffening, age, body fat composition, leptin/adiponectin ratio,

195 postprandial insulin and arterial stiffness indices were included in separate regression

196 models. Body fat composition and postprandial insulin remained independent 
197 predictors of AIx. Again, age remained the only significant $(P<0.0001)$ predictor of 198 PWV.

199

200

\section{Discussion}

201 The main findings of the study were that subjects who spend more time being 202 sedentary have stiffer arteries and more body fat. Conversely, subjects that spend 203 more time being active have less arterial stiffness and lower body fat. Unsurprisingly, 204 in this healthy population, age remained the strongest predictor of arterial stiffness. 205 However, body fat composition and postprandial insulin remained independent 206 predictors of AIx indicating the presence of a disease continuum whereby physical 207 inactivity and adiposity augment early vascular changes.

Our findings are similar with previous studies using objective methods to quantify daily physical activity. ${ }^{3,10,11}$ Previous studies report that carotid $\beta$-stiffness in

211 postmenopausal women is inversely correlated with time spent participating in low 212 intensity $(<4 \mathrm{MET})$ physical activity. ${ }^{23}$ In addition, further studies report that older 213 subjects, especially those with low cardiorespiratory fitness, that spend more time 214 being lightly active ( $<3$ METs) have less arterial stiffness, lower body fat, lower 215 blood pressure and lower fasting glucose. ${ }^{24}$ More recent research reports that physical 216 activity is an independent predictor of arterial stiffness in hypertensive adults with 217 varying degrees of metabolic disarray. ${ }^{10}$

219 In the present study, females had significantly higher AIx compared to males despite 220 no differences in age, heart rate and PWV were observed. Gender differences in AIx 221 are mainly attributable to differences in height. In shorter individuals, the pulse wave 
Physical activity and arterial stiffness

222 path length is smaller, and so, reflected waves coalesce with incident waves at an 223 earlier time point during systole resulting in greater AIx. ${ }^{25}$ These gender differences 224 are not observed for PWV because it is calculated relative to distance $\left(\mathrm{m} \cdot \mathrm{s}^{-1}\right)$.

225

226 The link between physical activity and arterial stiffness is complex. Physical activity 227 can benefit arterial stiffness via its direct effects on the vasculature or indirectly via 228 exercise induced changes in body composition and associated changes in metabolic 229 and cardiovascular risk factors.

230

231 Physical activity and exercise can directly benefit arterial stiffness and prevent 232 premature arterial ageing via its effect on blood pressure and heart rate. ${ }^{26,27}$ Blood 233 pressure is one of the major determinants of arterial stiffness. Exercise induced 234 changes in microvascular structure and function can directly affect systolic and 235 diastolic blood pressure, thereby improving arterial stiffness. ${ }^{28,29}$ Increased heart rate 236 negatively affects arterial stiffness via the viscoelastic effects of heart rate on the 237 arterial wall. ${ }^{30}$ Increased heart rate is also associated with increased sympathetic 238 outflow, which is known to stiffen large and medium sized vessels. ${ }^{31}$ In the present 239 study, no significant association was observed between 24-hour ambulatory or central 240 aortic blood pressure and physical activity and no association was observed between 241 physical activity and heart rate. These data suggest that the relationship between 242 physical activity, or lack thereof, and arterial stiffness was not mediated by the direct 243 effect of activity on the vasculature. 
245 Physical activity can also indirectly impact arterial stiffness via its affect on body 246 composition and subsequent alteration in adipose related inflammatory, metabolic and 247 hormonal factors. ${ }^{6}$

Obesity and adipose tissue distribution, specifically increased central/abdominal 250 visceral adipose tissue, is strongly correlated with increased arterial stiffness. ${ }^{8,432}$ 251 Activity induced changes in body fat composition can benefit arterial stiffness via 252 modification of inflammatory, metabolic and adipose related humoral factors. ${ }^{6,13,33}$

253

254 Non-specific systemic inflammatory markers, such as hsCRP and WCC, and adipose 255 associated inflammatory markers, such as interleukin-6 (IL6), tumour necrosis factor 256 alpha (TNF $\alpha)$ and monocyte chemoattractant protein 1 (MCP-1), are associated with 257 increased adiposity, premature vascular ageing and arterial stiffness. ${ }^{5,9,34}$ In the 258 present study, although the adipocytokines were not measured, hsCRP and WCC were 259 clinically normal and not associated with any of the activity parameters or indices of 260 arterial stiffness. These results suggest that abnormal immune responses were 261 probably not related to the activity related changes in arterial stiffness.

In the present study, all subjects had normal OGTT responses yet postprandial insulin 264 was inversely associated with time spent being moderately \& vigorously active and 265 independently associated with arterial stiffness. These results suggest that the 266 relationship between physical activity, arterial stiffness and adiposity may be 267 mediated via the deleterious affects of adiposity on endocrine function and glycaemic 268 homeostasis. In support of this, previous studies have consistently reported the 
Physical activity and arterial stiffness

269 relationship between abdominal/visceral adiposity, metabolic disorder and arterial

270 stiffness in both healthy and diseased populations. ${ }^{35,36}$

271

272 Leptin/adiponectin ratio was associated with time spent being sedentary and moderate

273 \& vigorous activity. The link between adiposity, leptin, adiponectin, metabolic

274 disarray and cardiovascular disease has been consistently reported. ${ }^{37,38}$ Furthermore, it

275 is suggested that hypertrophy of adipocytes, especially those at key anatomic

276 locations, results in abnormal paracrine function, disrupting vascular and metabolic

277 homeostasis. $^{39,40,41}$

278

279 In summary, the major findings of the present study were that time spent being 280 sedentary and time spent participating in moderate and vigorous activity was 281 associated with increased and decreased arterial stiffness and body fat. This is the first 282 study demonstrate the relationship between habitual physical activity and arterial wall 283 changes in healthy, middle-aged, life-long non-smoking subjects. Furthermore, the 284 results also indicate that adiposity and hyperinsulinaemia may be responsible for the 285 increased arterial stiffness in less active subjects. Future studies are needed to explore 286 the protective effect of physical activity and premature arterial stiffening or whether 287 weight loss alone is sufficient to actuate beneficial changes.

289 A major strength of the present study was that objective methods were used to 290 quantify daily habitual physical activity patterns. However, arbitrary activity 291 thresholds were used to determine time spent being sedentary, lightly active, 292 moderately active and vigorously active. Therefore, the relative intensity of the 293 activity categories may have differed for the wide age range of subjects (range: 21-59 
294 years) that participated in the study. Further studies adopting accelerometry as a 295 means to examine routine physical activity patterns should consider these factors.

296

297

\section{Funding source}

298 This study was partly funded by the Meath Foundation.

299

300

301

\section{References}

302

1. Nadar SK, Tayebjee MH, Messerli F, Lip GY. Target organ damage in 303 hypertension: pathophysiology and implications for drug therapy. Curr Pharm Des. 2006;12(13):1581-92.

305

2. Boreham CA, Ferreira I, Twisk JW, et al. Cardiorespiratory fitness, physical activity, and arterial stiffness: the Northern Ireland Young Hearts Project. Hypertension. 2004;44(5):721-6.

309

3. Gando Y, Yamamoto K, Murakami H, et al. Longer time spent in light physical 311 activity is associated with reduced arterial stiffness in older adults. Hypertension. $312 \quad 2010 ; 56(3): 540-6$.

4. Maher V, O'Dowd M, Carey M, et al. Association of central obesity with early 315 Carotid intima-media thickening is independent of that from other risk factors. Int $316 \quad$ J Obes (Lond). 2009;33(1):136-43. essential hypertension. Hypertension. 2005;46(5):1118-22. 
Physical activity and arterial stiffness

321 6. van de Laar RJ, Ferreira I, van Mechelen W, Prins MH, Twisk JW, Stehouwer

322 CD. Lifetime vigorous but not light-to-moderate habitual physical activity impacts 323 favourably on carotid stiffness in young adults: the Amsterdam growth and health 324 longitudinal study. Hypertension. 2010;55(1):33-9.

325

326 7. Tomiyama H, Hirayama Y, Hashimoto H, et al. The effects of changes in the 327 metabolic syndrome detection status on arterial stiffening: a prospective study. 328 Hypertens Res. 2006;29(9):673-8.

330 8. Lo J, Dolan SE, Kanter JR, et al. Effects of obesity, body composition, and 331 adiponectin on carotid intima-media thickness in health women. J Clin Endocrinol 332 Metab. 2006;91(5):1677-1682.

334 9. McEniery CM, Wilkinson IB. Large artery stiffness and inflammation. J Hum 335 Hypertens. 2005;19(7):507-9.

336

337 10. O'Donovan C1, Lithander FE, Raftery T, Gormley J, Mahmud A, Hussey J. 338 Inverse relationship between physical activity and arterial stiffness in adults with 339 hypertension. J Phys Act Health. 2014;11(2):272-7.

340

341 11. Sugawara J, Otsuki T, Tanabe T, et al. Physical activity duration, intensity, 342 and arterial stiffening in postmenopausal women. Am $J$ Hypertens. $343 \quad 2006 ; 19(10): 1032-6$. 
345 12. van der Laar RJ, Ferreira I, van Mechelan W et al. Lifetime vigorous but not

346 light-to-moderate habitual physical activity impacts favourably on carotid stiffness 347 in young adults: the Amsterdam Growth and Health Longitudinal Study. $348 \quad$ Hypertension. 2010;55:33-39.

349

350 13. Crespo CJ, Palmieri MR, Perdomo RP, et al. The relationship of physical 351 activity and body weight with all-cause mortality: results from the Puerto Rico 352 Heart Health Program. Ann Epidemiol. 2002;12(8):543-52.

353

354 14. Kelly R, Hayward C, Avolio A, O'Rourke M. Noninvasive determination of 355 age-related changes in the human arterial pulse. Circulation. 1989;80(6):1652-9.

15. Hickson SS, Butlin M, Broad J, Avolio AP, Wilkinson IB, McEniery CM. 358 Validity and repeatability of the Vicorder apparatus: a comparison with the 359 SphygmoCor device. Hypertens Res. 2009;32(12):1079-85.

360

361 16. Hale LA, Pal J, Becker I. Measuring free-living physical activity in adults with 362 and without neurologic dysfunction with a triaxial accelerometer. Arch Phys Med 363 Rehabil. 2008;89(9):1765-71.

364

365 17. Catellier DJ, Hannan PJ, Murray DM, et al. Imputation of missing data when 366 measuring physical activity by accelerometry. Med Sci Sports Exerc. $367 \quad 2005 ; 37: S 555-62$. 
Physical activity and arterial stiffness

369 18. Rowlands AV, Thomas PW, Eston RG, Topping R. Validation of the RT3

370 triaxial accelerometer for the assessment of physical activity. Med Sci Sports $371 \quad$ Exerc. 2004;36(3):518-24.

372

373 19. Trost SG, McIver KL, Pate RR. Conducting accelerometer-based activity $374 \quad$ assessments in field-based research. Med Sci Sports Exerc. 2005;37:S531-43.

376 20. Harrington, J., Perry, I., Lutomski, J., et al. SLÁN 2007: Survey of Lifestyle, 377 Attitudes and Nutrition in Ireland. Dietary Habits of the Irish Population, 378 Department of Health and Children. 2008.

380 21. Mattace-Raso F, Hofman A, Verwoert GC, et al. Determinants of pulse wave 381 velocity in healthy people and in the presence of cardiovascular risk factors: 382 'establishing normal and reference values'. Reference Values for Arterial Stiffness' 383 Collaboration. Eur Heart J. 2010;31(19):2338-50.

384

385 22. O'Brien E, Asmar R, Beilin L, et al. European Society of Hypertension 386 Working Group on Blood Pressure Monitoring.Practice guidelines of the 387 European Society of Hypertension for clinic, ambulatory and self blood pressure 388 measurement. Hypertens. 2005;23(4):697-701.

390 23. Sugawara J, Otsuki T, Tanabe T, et al. Physical activity duration, intensity, 391 and arterial stiffening in postmenopausal women. Am J Hypertens. $392 \quad 2006 ; 19(10): 1032-6$. 
394 24. Gando Y1, Yamamoto K, Murakami H, et al. Longer time spent in light 395 physical activity is associated with reduced arterial stiffness in older adults. 396 Hypertens. 2010;56(3):540-6.

397

398 25. McGrath BP1, Liang YL, Kotsopoulos D, Cameron JD. Impact of physical 399 and physiological factors on arterial function. Clin Exp Pharmacol Physiol. $400 \quad 2001 ; 28(12): 1104-7$.

401

402 26. Rueckert PA, Slane PR, Lillis DL, Hanson P. Hemodynamic patterns and 403 duration of post-dynamic exercise hypotension in hypertensive humans. Med Sci $404 \quad$ Sports Exerc. 1996;28(1):24-32.

405

406 27. Wallace JP, Bogle PG, King BA, Krasnoff JB, Jastremski CA.The magnitude 407 and duration of ambulatory blood pressure reduction following acute exercise. $J$ 408 Hum Hypertens. 1999;13(6):361-6.

409

410 28. Green DJ. Exercise training as vascular medicine: direct impacts on the 411 vasculature in humans. Exerc Sport Sci Rev. 2009;37(4):196-202.

413 29. Thijssen DH, Maiorana AJ, O'Driscoll G, Cable NT, Hopman MT, Green DJ. 414 Impact of inactivity and exercise on the vasculature in humans. Eur $J$ Appl $415 \quad$ Physiol. 2010;108(5):845-75.

416 
Physical activity and arterial stiffness

417 30. Park BJ, Lee HR, Shim JY, Lee JH, Jung DH, Lee YJ. Association between

418 resting heart rate and arterial stiffness in Korean adults. Arch Cardiovasc Dis.

$419 \quad 2010 ; 103(4): 246-52$.

420

421 31. Swierblewska E, Hering D, Kara T, et al. An independent relationship between 422 muscle sympathetic nerve activity and pulse wave velocity in normal humans. $J$ $423 \quad$ Hypertens. 2010;28(5):979-84.

424

425 32. Sutton-Tyrrell K, Newman A, Simonsick EM, et al. Aortic stiffness is 426 associated with visceral adiposity in older adults enrolled in the study of health, 427 aging, and body composition. Hypertension. 2001;38(3):429-33.

428

429 33. Faeh D, Braun J, Tarnutzer S, Bopp M. Obesity but not overweight is $430 \quad$ associated with increased mortality risk. Eur J Epidemiol. 2011;26(8):647-55.

431

432 34. Phillips AC, Jiang CQ, Thomas GN, et al. White blood cell subsets are 433 associated with carotid intima-media thickness and pulse wave velocity in an older 434 Chinese population: the Guangzhou Biobank Cohort Study. J Hum Hypertens. $435 \quad 2012 ; 26(8): 485-92$.

436

437 35. Cruickshank K, Riste L, Anderson SG, Wright JS, Dunn G, Gosling RG. 438 Aortic pulse-wave velocity and its relationship to mortality in diabetes and 439 glucose intolerance: an integrated index of vascular function? Circulation. $440 \quad 2002 ; 15: 106(16): 2085-90$. 
442 36. Webb DR, Khunti K, Silverman R, et al. Impact of metabolic indices on 443 central artery stiffness: independent association of insulin resistance and glucose $444 \quad$ with aortic pulse wave velocity. Diabetologia. 2010;53(6):1190-8.

445

446 37. Hajer GR, van Haeften TW, Visseren FL. Adipose tissue dysfunction in 447 obesity, diabetes, and vascular diseases. Eur Heart J. 2008;29(24):2959-71.

38. Hsueh WA, Law R. The central role of fat and effect of peroxisome 450 proliferator-activated receptor-gamma on progression of insulin resistance and 451 cardiovascular disease. Am J Cardiol. 2003;18:92(4A):3J-9J.

452

453

39. Bays HE, González-Campoy JM, Bray GA, et al. Pathogenic potential of 454 adipose tissue and metabolic consequences of adipocyte hypertrophy and 455 increased visceral adiposity. Expert Rev Cardiovasc Ther. 2008;6(3):343-68.

456

457 40. Li FY, Cheng KK, Lam KS, Vanhoutte PM, Xu A. Cross-talk between 458 adipose tissue and vasculature: role of adiponectin. Acta Physiol (Oxf). $459 \quad 2011 ; 203(1): 167-80$.

460

461 41. O'Connell J, Lynch L, Cawood TJ, et al. The relationship of omental and 462 subcutaneous adipocyte size to metabolic disease in severe obesity. PLoS One. $463 \quad 2010: 5(4): \mathrm{e} 9997$. 
Physical activity and arterial stiffness

\begin{tabular}{|c|c|c|}
\hline \multicolumn{3}{|c|}{$\begin{array}{l}\text { Physical, metabolic, endocrine, inflammatory and } \\
\text { haemodynamic characteristics }\end{array}$} \\
\hline & Male & Female \\
\hline $\mathrm{n}$ & $\mathrm{n}=51$ & $\mathrm{n}=28$ \\
\hline Age (years) & $38 \pm 9$ & $40 \pm 9$ \\
\hline Height $(\mathrm{cm})$ & $177.9 \pm 6.7$ & $164.4 \pm 5.2$ \\
\hline Body mass $(\mathrm{kg})$ & $83.1 \pm 13.9$ & $64.5 \pm 6.8$ \\
\hline BMI $\left(\mathrm{kg} \cdot \mathrm{m}^{2}\right)$ & $26.2 \pm 3.7$ & $23.9 \pm 2.9$ \\
\hline Waist (cm) & $91.9 \pm 11.8$ & $78.3 \pm 6.6$ \\
\hline Waist/Height & $0.52 \pm 0.06$ & $0.47 \pm 0.05$ \\
\hline Body fat $(\%)$ & $22.3 \pm 6.7$ & $30.1 \pm 5.3$ \\
\hline Total Cholesterol $\left(\mathrm{mmol} . \mathrm{L}^{-1}\right)$ & $3.20 \pm 0.75$ & $3.07 \pm 0.71$ \\
\hline Triglyceride $\left(\mathrm{mmol} . \mathrm{L}^{-1}\right)$ & $1.04 \pm 0.43$ & $0.87 \pm 0.29$ \\
\hline HDLc $\left(\mathrm{mmol} . \mathrm{L}^{-1}\right)$ & $1.33 \pm 0.36$ & $1.66 \pm 0.41 * * *$ \\
\hline LDLc $\left(\mathrm{mmol}^{-\mathrm{L}^{-1}}\right)$ & $2.72 \pm 0.68$ & $2.67 \pm 0.67$ \\
\hline Glucose fast $\left(\mathrm{mmol} \cdot \mathrm{L}^{-1}\right)$ & $5.17 \pm 0.39$ & $4.91 \pm 0.45$ \\
\hline Glucose PP (mmol. $\left.\mathrm{L}^{-1}\right)$ & $4.77 \pm 1.01$ & $4.92 \pm 1.20$ \\
\hline Insulin Fast (mU.L $\left.{ }^{-1}\right)$ & $7.56 \pm 2.82$ & $7.37 \pm 3.55$ \\
\hline Insulin PP (mU.L $\left.\mathrm{L}^{-1}\right)$ & $23.85 \pm 28.03$ & $27.52 \pm 23.94$ \\
\hline $\mathrm{HbA}_{1 \mathrm{c}}(\%)$ & $5.30 \pm 0.30$ & $5.21 \pm 0.31$ \\
\hline $\mathrm{HOMA}_{\mathrm{IR}}$ & $1.78 \pm 0.70$ & $1.65 \pm 0.77$ \\
\hline Leptin (pg.mL $\left.L^{-1} \cdot 10^{-2}\right)$ & $118.61 \pm 113.40$ & $137.88 \pm 78.03$ \\
\hline Adiponectin (pg.mL-1.10 $0^{-2}$ ) & $59.10 \pm 27.42$ & $60.68 \pm 32.19$ \\
\hline Lept/Adipo & $2.99 \pm 4.97$ & $2.77 \pm 1.88$ \\
\hline hsCRP (mg.L $\left.L^{-1}\right)$ & $2.5 \pm 2.89$ & $1.30 \pm 1.62$ \\
\hline $\operatorname{WCC}\left(10^{9} \cdot \mathrm{L}^{-1}\right)$ & $5.90 \pm 1.75$ & $5.87 \pm 1.71$ \\
\hline 24h Brachial Sys BP (mmHg) & $119 \pm 7$ & $111 \pm 9$ \\
\hline 24h Brachial Dia BP (mmHg) & $69 \pm 6$ & $66 \pm 7$ \\
\hline Aortic Sys BP (mmHg) & $109 \pm 8$ & $105 \pm 10$ \\
\hline Aortic Dia BP (mmHg) & $75 \pm 7$ & $71 \pm 7$ \\
\hline Heart rate (beats. $\min ^{-1}$ ) & $60 \pm 8$ & $63 \pm 9$ \\
\hline AIx $(\%)$ & $9.90 \pm 11.90$ & $21.75 \pm 10.67 * * * *$ \\
\hline $\operatorname{PWV}\left(\mathrm{m} \cdot \mathrm{s}^{-1}\right)$ & $6.88 \pm 0.91$ & $6.89 \pm 0.98$ \\
\hline
\end{tabular}

466 Table 1. Physical characteristics and risk factors. Body mass index (BMI), waist 467 height ratio (waist/height) high density lipoprotein cholesterol (HDLc), low density 468 lipoprotein cholesterol (LDLc), postprandial glucose (Glucose PP), postprandial 469 insulin (Insulin $\mathrm{PP}$ ), glycosylated haemoglobin $\left(\mathrm{HbA}_{1 \mathrm{c}}\right)$, homeostasis model 470 assessment of insulin resistance $\left(\mathrm{HOMA}_{\mathrm{IR}}\right)$, high sensitivity c-reactive protein 471 (hsCRP), white cell count (WCC), 24-hour ambulatory brachial systolic blood 472 pressure (24h Brachial Sys BP), 24-hour ambulatory brachial diastolic blood pressure 473 (24h Brachial Dia BP), aortic systolic blood pressure (Aortic Sys BP), aortic diastolic 474 blood pressure (Aortic Dia BP), augmentation index (AIx), pulse wave velocity 
1

2

3

4

5

6

7

8

9

10

11

12

13

14

15

16

17

18

19

20

21

22

23

24

25

26

27

28

29

30

31

32

33

34

35

36

37

38

39

40

41

42

43

44

45

46

47

48

49

50

51

52

53

54

55

56

57

58

59

60

Physical activity and arterial stiffness

475 (PWV). ** $\mathrm{P}<0.01, * * * \mathrm{P}<0.001, * * * * \mathrm{P}<0.0001$ significantly different compared to 476 males.

477 
Physical activity and arterial stiffness

478

\begin{tabular}{|l|cccc||c|}
\hline \multicolumn{7}{|c|}{$\begin{array}{c}\text { Univariate analysis of activity and physical, metabolic, endocrine, } \\
\text { inflammatory and haemodynamic characteristics }\end{array}$} \\
\hline \multicolumn{1}{|c|}{ Sed } & Light & Mod & Vig & Mod+Vig \\
& $\mathrm{r}$ & $\mathrm{r}$ & $\mathrm{r}$ & $\mathrm{r}$ & $\mathrm{r}$ \\
\hline Age & $0.30^{* *}$ & -0.11 & -0.03 & -0.20 & -0.13 \\
Body mass & 0.06 & -0.06 & 0.06 & -0.06 & 0.10 \\
BMI & 0.20 & -0.07 & -0.04 & -0.18 & -0.07 \\
Waist & 0.18 & 0.01 & -0.08 & -0.16 & -0.06 \\
W/Height & 0.23 & -0.01 & -0.18 & -0.20 & -0.16 \\
Body fat & $0.40^{* * *}$ & 0.04 & $-0.25^{*}$ & -0.21 & $-0.30^{*}$ \\
& & & & & \\
Total Cholesterol & 0.07 & -0.05 & 0.08 & -0.08 & -0.14 \\
Triglyceride & 0.10 & -0.01 & -0.20 & -0.10 & -0.16 \\
HDLc & -0.06 & -0.10 & 0.10 & 0.02 & 0.03 \\
LDLc & 0.16 & -0.03 & 0.04 & -0.11 & -0.14 \\
& & & & & \\
Glucose Fast & 0.18 & 0.01 & 0.00 & 0.08 & 0.01 \\
Glucose Post & 0.09 & 0.01 & -0.13 & 0.06 & -0.05 \\
Insulin Fast & 0.14 & -0.13 & -0.14 & -0.13 & -0.20 \\
Insulin Post & 0.19 & 0.02 & $-0.25^{*}$ & -0.21 & $-0.35^{* *}$ \\
HbA1c & -0.06 & 0.18 & 0.11 & -0.03 & 0.03 \\
HOMA & 0.18 & -0.14 & -0.15 & -0.12 & -0.20 \\
& & & & & \\
Leptin & 0.27 & 0.04 & -0.17 & -0.17 & -0.25 \\
Adiponectin & 0.05 & -0.23 & 0.16 & 0.10 & 0.07 \\
Lept/Adipo & 0.23 & 0.10 & -0.26 & -0.22 & $-0.28^{*}$ \\
hsCRP & 0.04 & 0.16 & -0.10 & 0.06 & -0.05 \\
WCC & -0.05 & -0.18 & -0.09 & 0.03 & -0.05 \\
24 h Sys & & & & & \\
24 h Dia & -0.07 & 0.07 & 0.12 & 0.02 & 0.17 \\
Aortic Sys & 0.14 & -0.01 & 0.07 & -0.14 & 0.01 \\
Aortic Dia & 0.18 & 0.01 & 0.01 & 0.02 & 0.07 \\
Heart rate & 0.10 & 0.00 & 0.07 & 0.12 & 0.13 \\
AIx & 0.02 & 0.02 & -0.04 & -0.13 & -0.09 \\
PWV & $0.38^{* * *}$ & -0.04 & -0.17 & -0.10 & $-0.28^{*}$ \\
Table 2. Spar & $0.33^{* *}$ & -0.23 & 0.00 & -0.18 & -0.12 \\
\hline
\end{tabular}

479 Table 2. Spearman's Univariate analysis of relative time spent being sedentary (Sed), 480 lightly active (Light), moderately active (Mod), vigorously active (Vig), combined 481 moderate \& vigorous activity (Mod+Vig) and indices of obesity, humoral factors and 482 arterial stiffness. $* \mathrm{P}<0.05, * * \mathrm{P}<0.01, * * * \mathrm{P}<0.001$. 
Physical activity and arterial stiffness

485

486 a)

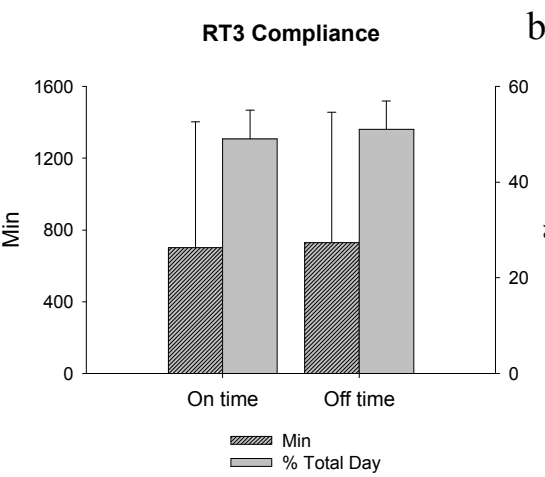

b)

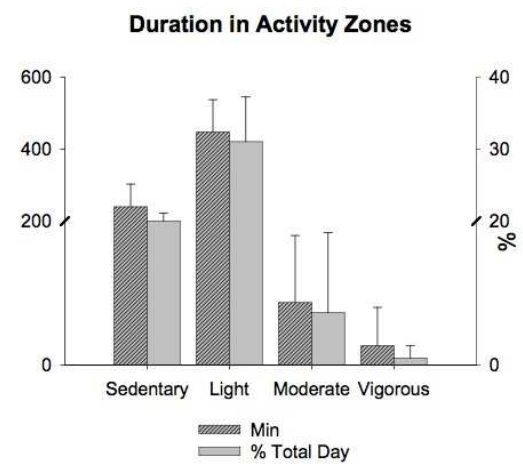

Figure 1. a) RT3 compliance. Absolute (min) and relative (\%) time spent wearing (On time) and not wearing (Off time) the RT3. b) Absolute (Min) and relative (\%) time spent within activity thresholds. Relative time is expressed as a percentage of an entire day (1440 $\mathrm{min})$. Results are mean $\pm \mathrm{SD}$. 


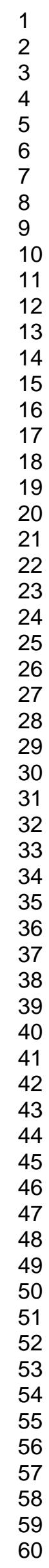

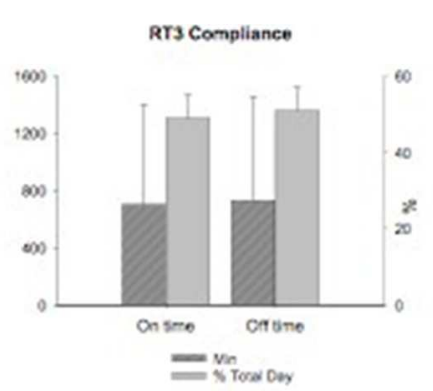

$62 \times 50 \mathrm{~mm}(72 \times 72 \mathrm{DPI})$

20

22

23

25

26

27

29

30

33

34

35

36

37

38

41

42

43

44

46

47

48

49

50

51

52

54

55

57

58

59

60

Human Kinetics, 1607 N Market St, Champaign, IL 61825 


1
2
3
4
5
6
7
8
9
10
11
12
13
14
15
16
17
18
19
20
21
22
23
24
25
26
27
28
29
30
31
32
33
34
35
36
37
38
39
40
41
42
43
44
45
46
47
48
49
50
51
52
53
54
55
56
57
58
60

\section{Duration in Activity Zones}

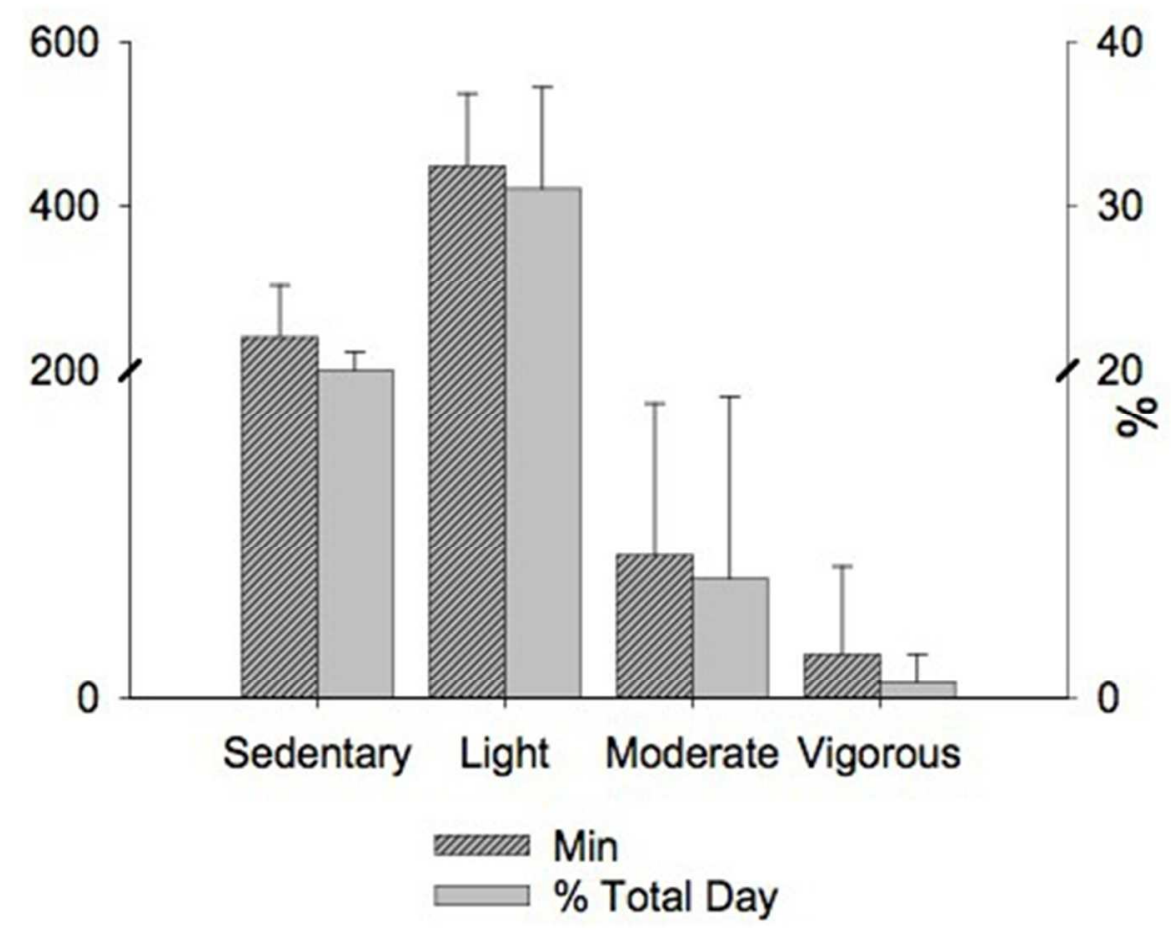

$174 \times 143 \mathrm{~mm}(72 \times 72 \mathrm{DPI})$ 